\title{
Analysis Characteristics Of Pendulum Oscillation In PLTGL-SB
}

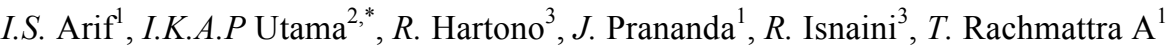 \\ ${ }^{1}$ Dept. of Marine Engineering, Institute of Technology Sepuluh Nopember, Indonesia \\ ${ }^{2}$ Dept. of Naval Architecture, Institute of Technology Sepuluh Nopember, Indonesia \\ ${ }^{3}$ Dept. of Physics Engineering, Institute of Technology Sepuluh Nopember, Indonesia
}

\begin{abstract}
Energy is an everlasting demand which sustains humanity and its activity throughout the world. The main problem energy for all country is still using fossil energy. Using fossil energy caused pollution and contaminate environment. Adopting Ocean wave energy we can convert the wave into eco-green energy. Wave energy in Indonesia very abundant, it's coastal line is 95,181 km number 2 in the world after Canada. The device that used to convert ocean wave energy into electrical energy is called WECs (Wave Energy Converters). Latterly, there are many kinds of WECs that already developed by an engineer. Pendulum system is one sample of WECs, its has uncomplicated working principle. Zamrisyaf is The man who first invented the device in 2010. Recently, the researcher still haven't found the parameter of pontoon geometry that can afford a good sea keeping for this WECs. In this research, the authors has been performed using experimental approach to test the pendulum system. The purpose of this study is to analyze the novel geometry of pontoon that identical to trimaran that can produce a large amplitude of pendulum oscillation through an experimental approach. The analyzed aspect is the combination of outrigger length, outrigger height, pendulum rod length, pendulum mass, and wave periods which have a maximum amplitude of pendulum oscillation. The analysis results show that the better solution is pontoon thus has outrigger height of $40 \mathrm{~mm}$, pendulum rod length of $106.7 \mathrm{~mm}$, outrigger length of $413 \mathrm{~mm}$, pendulum mass of 20, and wave periods of $0.8 \mathrm{~s}$ have a maximum amplitude of pendulum oscillation as big as 60 degrees.
\end{abstract}

\section{Introduction}

As energy demand increases, especially electrical energy in the world, it will result in an increasingly severe greenhouse effect as an effect of dependence on fossil energy sources [1]. Additionally, the dependence on fossil energy as an energy source can lead to other negative effects such as greenhouse gas emissions that lead to faster earth temperature rises, reduce energy supply, and cause geopolitical issues with respect to control of oil reserves that are at the core of some The issue of armed conflict in recent decades [2]. Due to all these problems the world is beginning to realize the importance of clean energy sources or renewable energy sources along with its conversion technology $[1,2]$. One source of renewable energy that has the potential to be converted into electrical energy is derived from the sea that can be broadly classified into several types, namely tidal energy, wave energy, ocean thermal energy, ocean currents energy, and sea wind energy and Salt gradient [3].

The three most common types of marine energy are tidal energy, wave energy, and ocean thermal energy [1]. Sea waves as one of renewable energy are known as resources that have the potential to be exploited in a sustainable manner to be converted into electrical energy [4].
As in the world, electricity demand in Indonesia is also increasing along with the times. In addition, there are at least three major groups of national energy problems: low electrification rates, dependence on fossil energy sources, and low utilization of renewable energy [5]. To pursue future energy needs the policy to be done is to integrate renewable and nonrenewable energy, with a greater change in the composition of use in renewable energy types. Indonesia itself is a maritime country with great wave energy potential.

Sea wave energy is a renewable energy that is continuous and environmentally friendly [5]. Tool to convert ocean wave energy into electrical energy is called Wave Energy Converter (WECs) [6]. To date, there have been several types of WECs that have been developed in the world, including submerged pressure differentials, oscillating wave surge converters, overtopping devices, oscillating water column, and others [7]. In addition, there is also a tool of ocean wave energy conversion into electrical energy developed by researchers from Indonesia that is using pendulum system or called as a wave powerhouse wave pendulum system (PLTGL-SB). The study of PLTGL of this pendulum system was first performed by Zamrisyaf, one of the PLN planning staffs in West Sumatra. The concept of a wave powerhouse of the pendulum system is simple, that is, by exploiting the fluctuation of the movement of

\footnotetext{
Corresponding author: kutama@na.its.ac.id
} 
sea water waves which will make the pendulum move like a bell, the movement is then transmitted into a rotary motion to move the dynamo then into electrical energy [8]. The power generated by the wave powerhouse of the pendulum system is much influenced by the dimensions of the pontoon, the length of the pendulum, and the mass of pendulum [9]. The parameters affecting the magnitude of power are the amount of torque associated with the amplitude and the frequency of the resulting vibration [10].

In previous studies, the observed pontoons were rectangles by Zamrisyaf. After examining the rectangular shape, research on the shape of the pontoon was again carried out with a circular pontoon, a square of eight, then a square of six. The best results for the wave height and the same period are obtained when the pontoon is square. Parameters that affect the motion of the pendulum itself is the stability of the pontoon used. In this final project will be investigated the power generated by PLTGL-SB system with cylindrical pontoon which has symmetrical outrigger on both sides. In addition, it will also examine the relationship of mass, length of the pendulum arm, the length of the outrigger sides, and the outrigger heights from the base to the torque generated by the pendulum. The research will be done through experiments in the laboratory by using a prototype that has a scale of $1: 10$ to the real dimension

\section{Methods}

\subsection{Literature Study}

In previous studies, the observed pontoons were rectangles by Zamrisyaf. After examining the rectangular shape, research on the shape of the pontoon was again carried out with a circular pontoon, a square of eight, then a square of six. The best results for the wave height and the same period are obtained when the pontoon is square. Parameters that affect the motion of the pendulum itself is the stability of the pontoon used.

In this final project will be investigated the power generated by PLTGL-SB system with cylindrical pontoon which has symmetrical outrigger on both sides. In addition, it will also examine the relationship of mass, length of the pendulum arm, the length of the outrigger sides, and the outrigger heights from the base to the torque generated by the pendulum. The research will be done through experiments in the laboratory by using a prototype that has a scale of 1:10 to the real dimension.

\subsection{Analytical Calculation}

Once determined the dimensions of the pontoon prototype will be made, then the analytical calculation to support the data so that it can be known combination of sizes in accordance with the desired specification, the condition where the pontoon continues to shake but still in a stable positive condition. The dimensions of the selfmade pontoon prototype are $32 \mathrm{~cm}$ long cylinders with $16.5 \mathrm{~cm}$ diameter. which has a symmetrical outrigger on both sides as long as $32 \mathrm{~cm}$ with a diameter of $4 \mathrm{~cm}$. A pendulum made is a vertical pendulum. While the given wave direction is 90 degrees from the face of the pontoon.

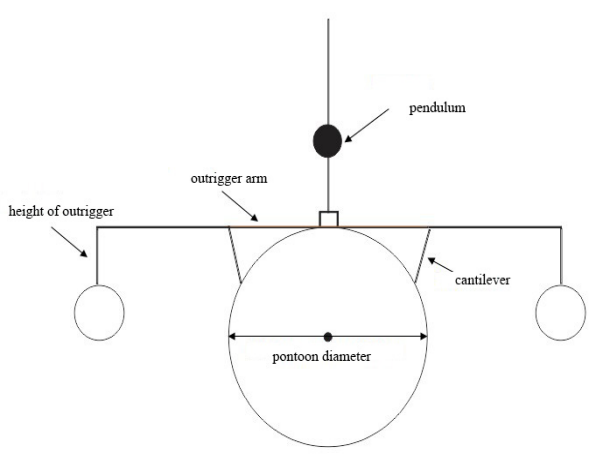

Fig. 1. Front view of Pontoon Design.

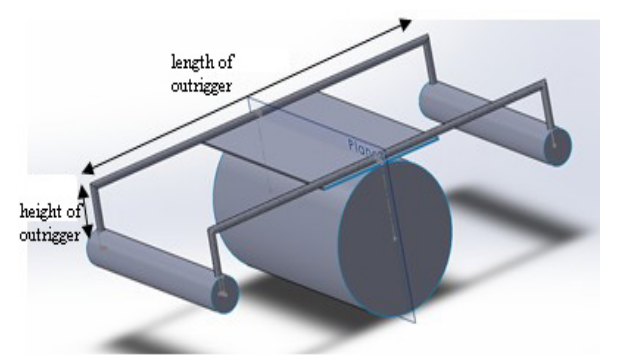

Fig. 2. Pontoon 3D Design.

Specification of the design of the pontoon prototype to be performed calculation analysis is as follows:

Large Cylinder Diameter: $16.5 \mathrm{~cm}$

Large Cylindrical Thickness: $0.7 \mathrm{~cm}$

Small Cylinder Diameter: $4 \mathrm{~cm}$

Thickness of Small Cylinders: $0.2 \mathrm{~cm}$

Large Cylinder Length: $32 \mathrm{~cm}$

Small Cylinder Length: $32 \mathrm{~cm}$

Mass Cylindrical Type: $1.39 \mathrm{gr} / \mathrm{cm} 3$

Full: $1 / 2$ and $2 / 3$ diameter of pontoon

High of Outrigger: $1.5 \mathrm{~cm}$ and $4 \mathrm{~cm}$

Plate length: $32 \mathrm{~cm}$

Plate width: $17 \mathrm{~cm}$

Plate Density: $1.2 \mathrm{gr} / \mathrm{cm} 3$

Once determined the main size of the pontoon dimension along with the materials used, then calculated parameters that will determine the stability of the prototype made. The parameters are $\mathrm{COB}, \mathrm{COG}$, and metacenter. The first thing to be calculated is to determine the mass of each component so that it can be known the total mass of the whole system. The mass calculation can be done with $\mathrm{Q}$ is the density of the object and V is the volume of the object. After the mass of the object is found, it is necessary to look for the weight of the object as equation 2. 


$$
\begin{aligned}
m_{\text {tot }} & =\sum \rho_{n} V_{n} \\
B_{\text {tot }} & =\sum m_{n} g
\end{aligned}
$$

When the weight of each component and total weight has been found, the center of gravity (COG) can be searched using equation 3 where $B$ is the weight of the object and 1 is the center point of each section in terms of the abscissa axis.

$$
\operatorname{COG}=\frac{B_{1} l_{1}+B_{2} l_{2}+B_{n} l_{n}}{B_{\text {tot }}}
$$

Meanwhile, to find the value of the center of buoyancy (COB), will be more easily searched because we have determined from the beginning the size of the submerged pontoon. $\mathrm{COB}$ is likened to $\mathrm{COG}$ from the submerged parts, so the search will be the same as COG with a record of just the submerged pontoon that is used as a review. Thus, $\mathrm{COB}$ can be searched using equation 4 .

$$
\mathrm{COB}=\frac{\underline{\mathrm{B}}_{\text {submerged }} \cdot \underline{l}_{\text {submerged }}}{\mathrm{B}_{\text {submerged }}}
$$

The next step is to calculate the metacenter of the pontoon. Metacenter itself can be searched using equation 5 with $\mathrm{I}_{0}$ is the moment of system inertia, $\mathrm{V}_{\mathrm{t}}$ is the volume of the pontoon submerged, and $\mathrm{G}_{0} \mathrm{~B}_{0}$ is the distance between $\mathrm{COG}$ and $\mathrm{COB}$.

$$
M=\frac{I_{0}}{V_{t}}-G_{0} B_{0}
$$

On a floating object, the magnitude of the Archimedes style will be the same as the force of gravity. So from the principle, we can know how big the submerged so that we can find out how big ballast needed for the pontoon can reach laden pre-determined. Then to determine the ballast, can be searched as equation 6 to 8 with of is the fluid type mass, $V_{t}$ is the volume of the submerged pontoon, ms is the total mass of the system so that the pontoon can be submerged in accordance with the specified load, and $g$ is the acceleration of earth gravity.

$$
\begin{aligned}
F a & =m_{s} g \\
\rho_{f} V_{t} g & =m_{s} g \\
m_{s} & =\rho_{f} V_{t}
\end{aligned}
$$

If the mass of the system has been obtained, then the ballast can be found by reducing the mass of the system with the total mass of the pontoon previously calculated using equation 1 .

\subsection{Determination of Prototype}

After the analytical calculation, it can be determined the feasibility of the prototype related with specifications that have been in accordance with the purpose of research. If at the previous calculation the metacenter point is at the top, followed by $\mathrm{COG}$, then $\mathrm{COB}$, then the pontoon has stabilized positively so that a predetermined specification can be made.

In this experiment, there were 48 variations with 3 variations of wavelength periods, 2 variations of the outer sleeve length, 2 variations of the outrigger that can be represented by water-laden, 2 variations of pendulum arm length, and 2 pendulum mass variations. The wave height used in the data retrieval process is $1.5 \mathrm{~cm}$ for all variations.

\subsection{Prototype Fabrication}

After the analytical calculation and determination of the dimensions of the pontoon, the prototype can be fabricated in accordance with the design specifications. Figures 3 and 4 show the pontoon prototype that has been created.

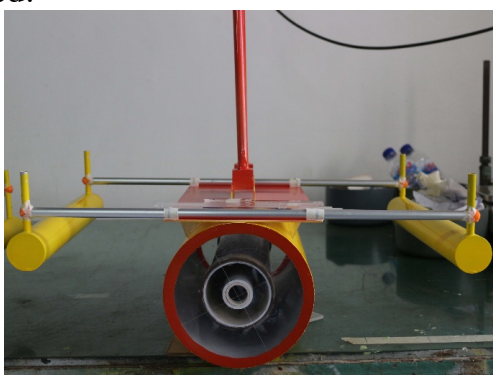

Fig. 3. Pontoon with ballast $2.3 \mathrm{~kg}$.

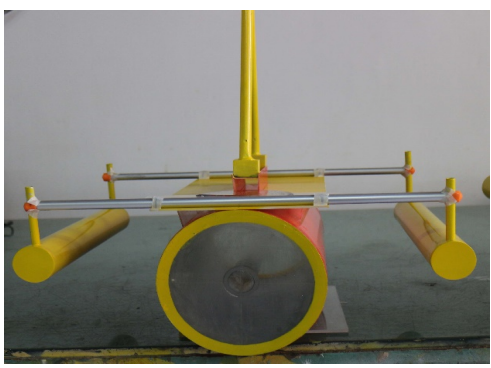

Fig. 4. Pontoon with ballast $1.2 \mathrm{~kg}$.

\subsection{Data Retrieval}

In this experimental study, the data were collected in the towing tank of Hydrodynamics Laboratory of Marine Faculty Technology-ITS. Which has a length of $50 \mathrm{~m}$, width $3 \mathrm{~m}$, and a depth is $2 \mathrm{~m}$. The data taken is the video movement of the pontoon and pendulum to know the deviation, as well as the amplitude of the roll and heave of the pontoons using sensors that have been available in the laboratory.

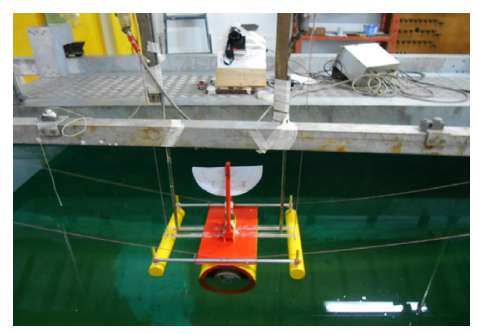

Fig. 5. Setting tool for data retrieval 


\subsection{Data Analysis and Paper Making}

As mentioned in Section 3.5, the data obtained from the experiments are the roll and heave drift of the pontoon and also the videotape of the pendulum data. The first thing to do is to process the video so that the data of pendulum deviation is quantitative. After the data obtained pendulum deviation and also pontoons, then done through data so that obtained graphs and tables that can represent the data. In addition, it is necessary to calculate the power generated by each condition of the experiments performed. Before sought power, the torque value $(\tau)$ must be known. The torque can be admitted applying equation 8 where $\mathrm{m}$ is the pendulum mass, $\mathrm{g}$ is the acceleration of gravity, 1 is the length of the pendulum arm, and $\theta$ is the confluence at the pendulum oscillation.

$$
\tau=m g l \sin \theta
$$

In addition to torque, the angular velocity of the pendulum oscillations should also be known. The angular velocity of the pendulum itself can be determined using the equation 9 with $g$ is the acceleration of gravity, 1 is the length of the pendulum arm, and $\mathrm{h}$ is the difference of the pendulum height when in the $\theta$ junction which can be searched using equation 10. After knowing torque and angular velocity, power can be searched using equation 11 .

$$
\begin{aligned}
& \omega=\frac{\sqrt{2 g h}}{l} \\
& h=h-h \cos \theta \\
& P=\tau \omega
\end{aligned}
$$

After all the data is processed, then the preparation of the making paper which is the final stage of this research project work and do as delivery of results and analysis of the implementation of research programs. The paper refers to the previous stages and describes the entire process of activity using a particular systematic.

\section{Results and Discussion}

\subsection{Pontoon Dimension}

The tested pontoon is a prototype with a ratio of $1: 10$. Prototype pontoons are made of cylindrical shape with outrigger symmetrical on both sides with a length of 320 $\mathrm{mm}$. The diameter of the pontoon is $165 \mathrm{~mm}$, while the outrigger has a diameter of $40 \mathrm{~mm}$. For the pendulum used consisted of 2 variations of mass, ie 20 grams and 40 grams with the variation of arm length $106.7 \mathrm{~mm}$ and $165 \mathrm{~mm}$. For more details, the shape of the prototype and pendulum can be seen in the picture below.

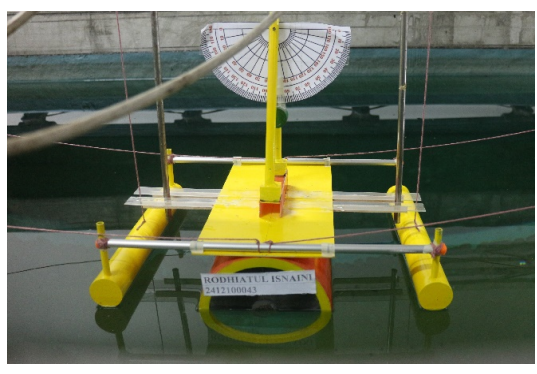

Fig. 6. Dimension of the pontoon with ballast $1.2 \mathrm{~kg}$.

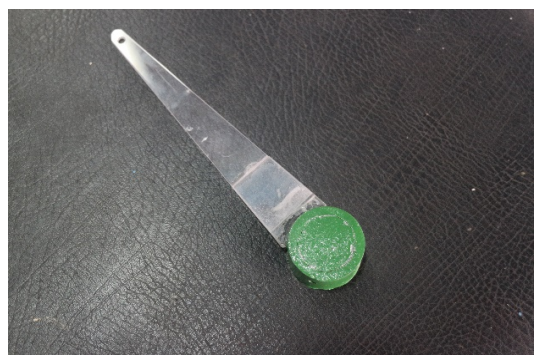

Fig. 7. Pendulum with mass 20 gram and arm length 106.7 $\mathrm{mm}$.

\subsection{Mass Calculation, Volume and Stability of Pontoons}

Once the geometry of the pontoon is determined, it is necessary to calculate the stability of the pontoon when exposed to the excitation force of the wave. The thing that most affects the stability of an object when immersed in water is the number of submerged parts of the object. The height of the part of the object dyed in the water is called as laden (t). If the load is known, then the center of buoyancy (COB) will also be known. To know all the data, it is necessary to calculate the mass and volume of the pontoon to be investigated.

Table 1. Weight of pontoon and pendulum construction.

\begin{tabular}{|l|l|r|r|r|}
\hline No. & $\begin{array}{l}\text { Part of } \\
\text { Pontoon }\end{array}$ & \multicolumn{1}{|l|}{$\begin{array}{l}\text { Volume } \\
\left(\mathrm{cm}^{3}\right)\end{array}$} & \multicolumn{1}{l|}{$\begin{array}{l}\text { Density } \\
\left(\mathrm{gr} / \mathrm{cm}^{3}\right)\end{array}$} & \multicolumn{1}{l}{$\begin{array}{l}\text { Mass } \\
(\mathrm{gr})\end{array}$} \\
\hline 1. & Pontoon & 1076.58 & 1.39 & 1496.45 \\
\hline 2. & Outrigger & 147.95 & 1.39 & 205.66 \\
\hline 3. & $\begin{array}{l}\text { Cover of the } \\
\text { pontoon }\end{array}$ & 213.72 & 1.20 & 256.46 \\
\hline 4. & $\begin{array}{l}\text { Cover of the } \\
\text { outrigger }\end{array}$ & 25.12 & 1.20 & 30.14 \\
\hline 5. & $\begin{array}{l}\text { Outrigger } \\
\text { arm }\end{array}$ & 7.61 & 2.71 & 57 \\
\hline 6. & $\begin{array}{l}\text { Outrigger } \\
\text { arm 2 }\end{array}$ & 6.33 & 2.71 & 47.8 \\
\hline 7. & $\begin{array}{l}\text { Height of } \\
\text { outrigger }\end{array}$ & 15.2 & 2.71 & 70.68 \\
\hline 8. & $\begin{array}{l}\text { Pendulum } \\
\text { construction }\end{array}$ & - & - & 80.00 \\
\hline
\end{tabular}

Based on the calculation, then obtained the total mass of the pontoon along with construction outrigger and pendulum that is equal to $2.12 \mathrm{~kg}$. The selected self is 0.5 and 0.67 diameter of the pontoon. Through analytical 
calculations, it can be obtained that the location of $\mathrm{COB}$, $\mathrm{COG}$, and metacenter point in accordance with the theory of stability so that the pontoon can return to its original position (stable positive).

$$
f^{G}
$$

Fig. 8. Position points for positive stable objects $(\mathrm{K}=\mathrm{keel}$, $\mathrm{B}=\mathrm{COB}, \mathrm{G}=\mathrm{COG}$, and $\mathrm{M}=$ metacenter)

According to calculations, the mass of the system that is equal to $2.12 \mathrm{~kg}$. However, with the desired weight of $2.12 \mathrm{kgs}$ is not reached, the ballast is required. Data on point COG, COB, metacenter, and also ballast can be seen in table 2 .

Table 2. Formatting sections, subsections and subsubsections.

\begin{tabular}{|r|r|r|r|r|}
\hline Draught & $\begin{array}{l}\text { COG } \\
(\mathrm{cm})\end{array}$ & $\begin{array}{l}\text { COB } \\
(\mathrm{cm})\end{array}$ & $\begin{array}{l}\text { Metacent } \\
\text { er }(\mathrm{cm})\end{array}$ & $\begin{array}{l}\text { Ballast } \\
(\mathrm{kg})\end{array}$ \\
\hline $0.5 \mathrm{D}$ & 8.67 & 7.49 & 12.17 & 1.2 \\
\hline $0.67 \mathrm{D}$ & 9.26 & 7.68 & 11.78 & 2.3 \\
\hline
\end{tabular}

\subsection{Experimental Results of Pontoon and Pendulum Deviation}

The number of variations tested was 48, with 3 variations of wavelength period, 2 variations of the outrigger sides, 2 variations of outrigger height, 2 pendulum arm variations, and 2 pendulum mass variations.In general, the oscillation characteristics of the experimental results are divided into 4 major sections. The first characteristic is that there is no oscillation at all. This phenomenon occurs in variations that are given a coming wave with a period of 0.4 seconds.

The second characteristic is when the pendulum oscillates with a smaller amplitude equal to 20 degrees. This phenomenon occurs in several variations of the pontoon given the wave style with a period of 0.6 or 0.8 seconds.The third characteristic is that the pendulum vibrates back and forth, not oscillating as expected by the researcher. This phenomenon occurs in 5 variations given the wave style with a period of 0.6 seconds (variation 17, variation 26, variation 32, variation 38 , variation 47).

The fourth characteristic is when the amplitude of the pendulum oscillation is of great value, ie more than 20 degrees. This fourth characteristic occurs in some variations that are given waves with periods of 0.6 and 0.8 seconds.
From the four characteristics mentioned above, the fourth type is eligible to be used as an ocean wave power plant because it produces a large amplitude of oscillation so that it can produce great power as well. From several variations on the incoming of the fourth characteristic, there are three variations that produce the largest amplitude and maximum amplitude, ie variations 12,36 , and 42. Figure 9 to 11 shows the result of pendulum oscillation along with the heaving value and rolling of pontoons on each of these variations.

The largest mean amplitude occurring at the timetested was a pontoon of variation 12 with an average amplitude value of 41.82 degrees and a maximum amplitude of 60 degrees. While the average amplitude at 36 and 42 variations in a row is 36.52 degrees and 32.54 degrees respectively. Variation 12 produces the largest pendulum shrinkage value because it is the most appropriate combination to obtain large amplitude.

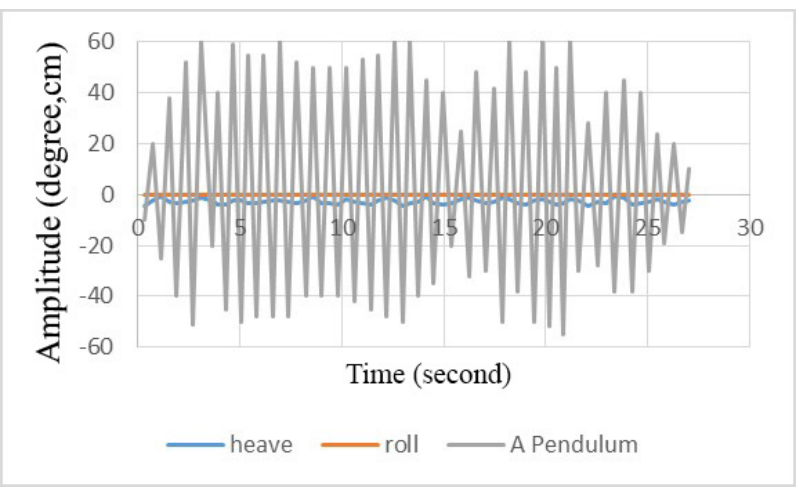

Fig. 9. Motion of pontoon and pendulum for variation 12 $(\mathrm{T}=0.8 \mathrm{~s} ; \mathrm{Pc}=413 \mathrm{~mm} ; \mathrm{Hc}=40 \mathrm{~mm} ; \mathrm{Lp}=106.7 \mathrm{~mm} ; \mathrm{Mp}=20 \mathrm{gr})$

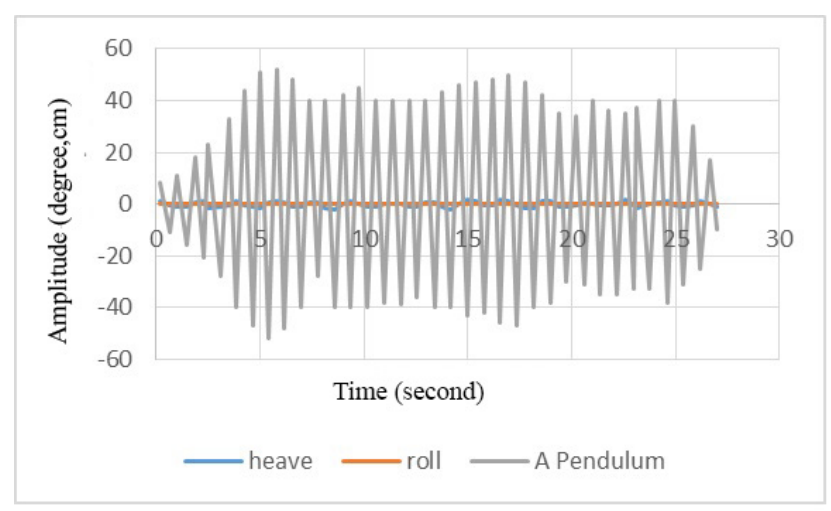

Fig. 10. Motion of pontoon and pendulum for variation 36 $(\mathrm{T}=0.8 \mathrm{~s} ; \mathrm{Pc}=495 \mathrm{~mm} ; \mathrm{Hc}=15 \mathrm{~mm} ; \mathrm{Lp}=106.7 \mathrm{~mm} ; \mathrm{Mp}=20 \mathrm{gr})$ 


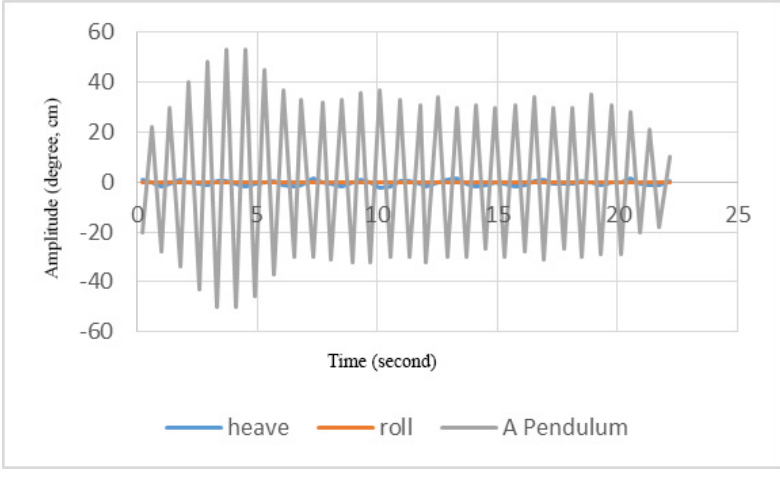

Fig. 11. Motion of pontoon and pendulum for variation 42 ( $\mathrm{T}=0.8 \mathrm{~s} ; \mathrm{Pc}=413 \mathrm{~mm} ; \mathrm{Hc}=15 \mathrm{~mm} ; \mathrm{Lp}=106.7 \mathrm{~mm} ; \mathrm{Mp}=20$ gr)

If the dimensional analysis is used, then when enlarged to the original scale variation 12 has a pontoon finger size of $1.65 \mathrm{~m}$, outrigger fingers of $0.4 \mathrm{~m}$, pontoon length and outrigger $3.2 \mathrm{~m}, 4.13 \mathrm{~m}$ outrigger, outrigger $0.4 \mathrm{~m}$, pendulum arm $1.067 \mathrm{~m}$, and pendulum mass of 20 $\mathrm{kg}$.

\subsection{Effect of Variables on Pendulum Oscillation}

After 48 experiments, the effect of the related variables on the pendulum oscillation. Data obtained that the greater the given wave period, the amplitude of the pendulum oscillation will also be greater. The greater the wave period does cause the rolling angle to become smaller, but not so with the rolling speed that occurs. If the rolling speed is large, the frequency of the pontoon vibrates also will be faster so that the pendulum will more easily oscillate.

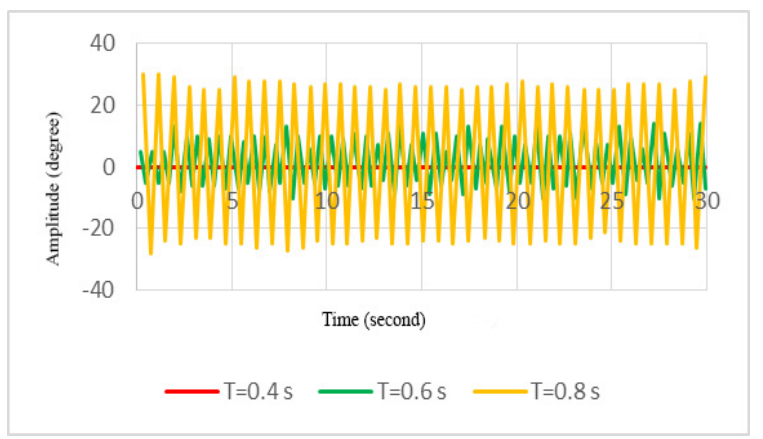

Fig. 12. Pendulum oscillations with different wave periods

Based on Figure 13 the variation of 15 is when the pontoon has an outrigger with a $495 \mathrm{~mm}$ sleeve length from end to end, whereas, in variation 12 , the length of the outrigger arm from end to end is $413 \mathrm{~mm}$. Based on the experiment, we can see if the length of the outrigger arm is greater, the average amplitude generated by the pendulum oscillation will be smaller. At the time of variation 12 (outrigger sleeve $=413 \mathrm{~mm}$ ), the average amplitude of pendulum oscillation is 41.82 degrees with a vibration frequency of $1.23 \mathrm{~Hz}$. Whereas when a variation of 15 that has a $495 \mathrm{~mm}$ outrigger sleeve, the pendulum will oscillate with a maximum amplitude of
21.44 degrees and a frequency of $1.355 \mathrm{~Hz}$. According to D. R. Berrett and C. B. Barrass (1999) by increasing the width of the ship (the length of the vessel is considered fixed), the vessel will be more stable [11]. This is what happens to the pontoon tested by the author. Seen in Figure 13 that the pontoon variation 15 with the larger outrigger sleeve length has a smaller rolling motion, then as a consequence, the pendulum oscillation will have a smaller amplitude as well.

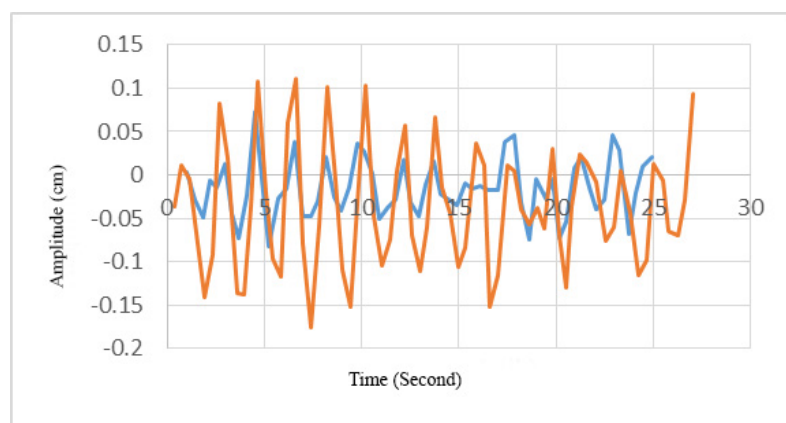

Fig. 13. Rolling motion for variation 12 and 15

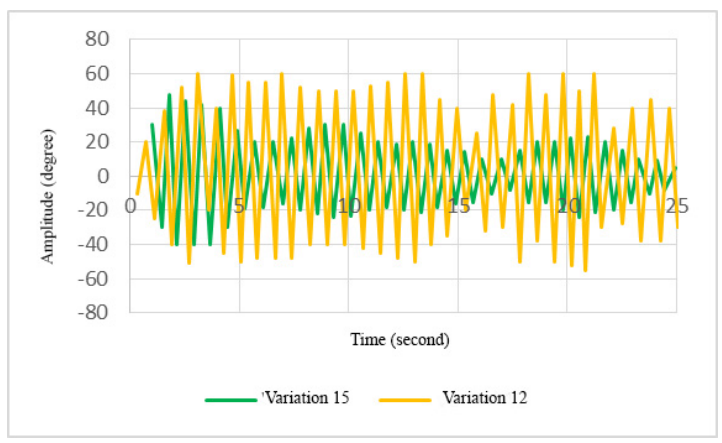

Fig. 14. Pendulum oscillation with changes of the outrigger arm length

In this experiment, changes in the outrigger level will affect the magnitude of the pontoons that are submerged in water. The bigger the outrigger, the value of the pontoon will be smaller. The larger-laden pontoon (variation 27, laden as high as $106.7 \mathrm{~mm}$ ) has a larger rolling amplitude compared to the $82.5 \mathrm{~mm}$ loaded pontoon. Comparison of this rolling motion can be seen as figure 16. The larger rolling amplitude is why the variation 27 has a greater oscillation amplitude compared to the variation 6 .

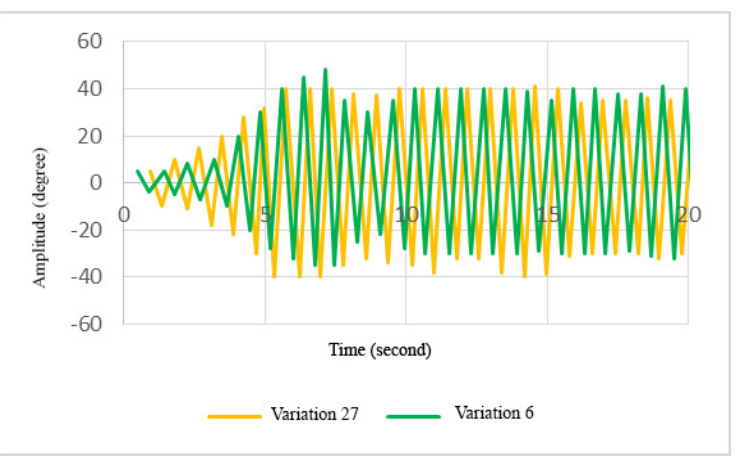

Fig. 15. Pendulum oscillation with outrigger high change 


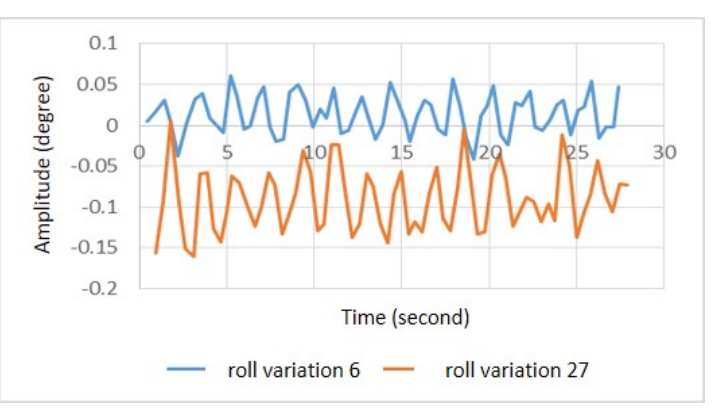

Fig. 16. Motion rolling when variations 6 and 27

If we see again equation 2.9 it can be seen that the mass will be inversely proportional to the size of the pendulum. This also happens to experiments that have been done by the author. It can be seen figure 17 that the pontoon with a variation of 18 having a pendulum mass of 40 grams has a mean deviation smaller than when the pontoon tested is a variation of 21 with a pendulum mass of 20 grams. The pendulum amplitude at variation 18 is 16.61 degrees, while variation 21 has an average pendulum oscillation amplitude of 19.32 degrees. The frequency of the pendulum oscillation itself does not have a significant difference value so that in the calculation of power will not be too much effect.

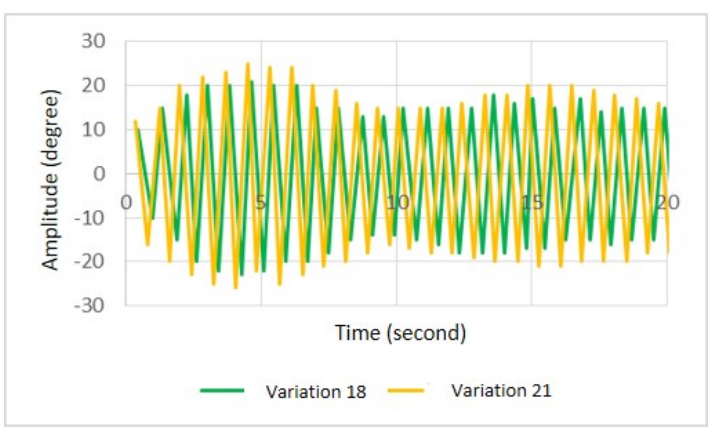

Fig. 17. Pendulum oscillation with mass changes

We can see that the root of the pendulum arm will be proportional to the period. The angular deviation from the pendulum will be inversely proportional to the period. So it can be concluded that the shorter the pendulum arm the larger the deviation. This is why the pendulum pendants with longer pendulum sleeves have smaller deviations compared to pendulums with shorter arms as shown in Figure 18. Variation 30 was pontoon with pendulum sleeve of $106.7 \mathrm{~mm}$ with mean pendulum value of 38.01 degrees, while variation 33 has pendulum arm length of $165 \mathrm{~mm}$ with average pendulum deviation value of 31.87 degrees.

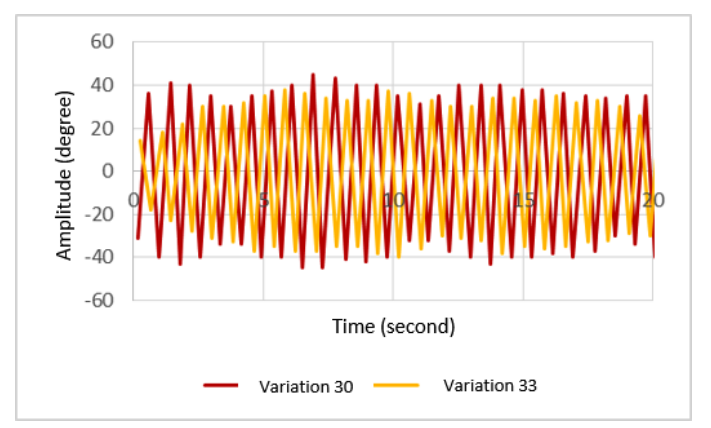

Fig. 18. Pendulum oscillation with pendulum arm length change

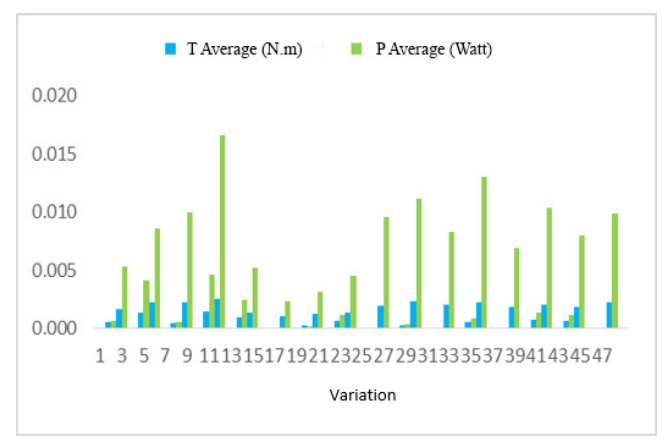

Fig. 19. Torque, angular velocity, and average power on each variation

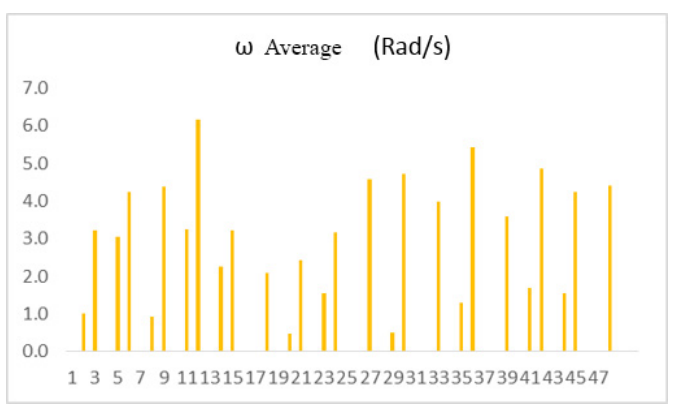

Fig. 20. Average angular velocity on each variation

Based on analytical calculations, it was found that the power obtained for variation 12 is 0.017 watts with an average angular velocity of $6.173 \mathrm{~m} / \mathrm{s}$.

\section{Conclusion}

Referring to the results of data analysis and discussion in the previous chapter, it can be taken some conclusions about this experimental study as follows. The amplitude of the pendulum oscillation decreases as the length of the outrigger arm, the outrigger, the pendulum mass, and the length of the pendulum arm have, but unlike the rise of the wave period, the pendulum oscillation amplitude increases as the parameter increases.

The variations that resulted in the maximum deviation value and the largest mean deviation were variation 12 with the wave period $0.8 \mathrm{~s}$, the outer sleeve length $413 \mathrm{~mm}$, the outrigger height $40 \mathrm{~mm}$, the pendulum arm length of $106.7 \mathrm{~mm}$, and the pendulum mass of 20 grams with a maximum deviation of 60 degrees and an average deviation of 41.82 degrees.

Some things that can be suggested from the results of this research for the continuation of its development. Further research can be a variation of the influence of the direction of the arrival of the wave of pontoon movement which will affect the pendulum oscillation. Data retrieval on subsequent variations is done when the water conditions in the towing tank are completely quiet. In addition, the sensor also needs to be checked each turn of variation so that the data obtained can be really ideal and accurate. 


\section{References}

1. Indonesia Energy Outlook 2014, Badan Pengkajian dan Pengembangan Teknologi , (2014).

2. Pengenalan Teknologi Pemanfaatan Energi Angin, Tasikmalaya: Tim Lentera Angin Nusantara, (2014).

3. Tutorial Blade 3 Dimensi, Tasikmalaya: Tim Lentera Angin Nusantara, (2015).

4. H. Piggot, Windpower Workshop: Building Your Own Wind Turbine, Centre of Alternative Technology Publications.

5. M. H. O.L., Aerodynamics of Wind Turbine, Second Edition, London, (2008).

6. S. Mehrangiz, Y. Emami, S. H. S. Sadigh and A. Etemadi, " Various Technologies for Producing Energy from Wave: A Review," International Journal of Smart Grid and Clean Energy, vol. 2, no. 2, pp. 289-294, (2013).

7. G. Iglesias, M. Alvarez and P. Garcia, "Wave Energy Converters," EOLLS, vol. 55, pp. 235-241, (2013).

8. H. T. Benbouzid and M. Benbouzid, "An Up-to-Date Technologies Review and Evaluation," INTERNATIONAL REVIEW OF ELECTRICAL-IREE, vol. 10, no. 1, pp. 56-61, (2015).

9. J. Falnes, "A review of wave-energy extraction," Science Direct Marine Structure, vol. 20, pp. 185-201, (2007).

10. F. Triatmojo, "Dinamika Kebijakan Diversifikasi Energi di Indonesia : Analisis Kebijakan Pengembangan Energi Terbarukan di Indonesia," Jurnal Ilmiah Administrasi Publik dan Pembangunan, vol. 4, pp. 146-159, (2013).

11. B. Bryan and D.R. Derrett, Ship Stability For Masters And Mates, Oxford, UK: Butterworth-Heinemann, (2006). 